\title{
Psychological and metabolic stress: A recipe for accelerated cellular aging?
}

\author{
Elissa S. Epel \\ University of California, Department of Psychiatry, San Francisco, California, USA
}

\begin{abstract}
Chronic stress can affect human health through a myriad of behavioral and biochemical pathways. This review focuses on some key hormonal and metabolic pathways that appear important today. In modern society, we are faced with excessive psychological stress, as well as an epidemic of overeating, and the two together appear to have synergistic effects. Chronic stress can lead to overeating, co-elevation of cortisol and insulin, and suppression of certain anabolic hormones. This state of metabolic stress in turn promotes abdominal adiposity. Both the direct stress response and the accumulation of visceral fat can promote a milieu of systemic inflammation and oxidative stress. This biochemical environment appears to be conducive to several cell aging mechanisms, mainly dampening telomerase and leading to telomere length (TL) shortening and cell senescence. Immune cell telomere shortness is linked with many chronic disease states and earlier mortality. In this way, chronic stress may influence a variety of diseases through a biochemical cascade leading to immune cell senescence. Certain psychological temperaments at high risk of this stress cascade (mainly anxiety prone), gene-environment interactions, and potential interventions for interrupting the stress-aging cascade are discussed.
\end{abstract}

Keywords: Cortisol, Insulin, Obesity, Oxidative stress, Psychological stress, Telomerase, Telomere Length

\section{A. INTRODUCTION}

Chronological age is the best predictor of chronic diseases. The elderly population (65 and older) is projected to increase significantly, reaching 72 million in the United States by $2030 .{ }^{1}$ Since the burden of diseases of aging on the healthcare system will likely be overwhelming, it is important to gain a deeper

Address for correspondence:

Elissa S. Epel, 3333 California Street, Suite 465, San Francisco, CA 94143, USA Tel.: (415) 476-7648, Fax: (415) 476-7744, E-mail: eepel@lppi.ucsf.edu Received 23-10-08, Revised 30-11-08, Accepted 10-12-08 understanding of biological aging. The development of age-related diseases occurs at different rates in different individuals, and psychological distress appears to be an important factor promoting earlier onset of age-related diseases..$^{2-6}$ Thus, better understanding of how stress is likely to promote "biological aging" may lead to clinical interventions or policies that could have a broad public health impact.

Below is a selective review of some of the major effects of chronic stress on metabolism and cell aging. It demonstrates how a stress-induced anabolic/ catabolic imbalance-characterized in part by high 
cortisol, glucose, and insulin, and low androgens and growth hormones-may lead to oxidative stress and systemic inflammation, which in turn impair cell aging processes. Consumption of energy-dense food and obesity also play a key mediating role in this pathway. Our modern lifestyle drives us to consume calorically dense food during times of stress. Both chronic stress arousal and overeating can cause insulin resistance, and together they promote energy storage in abdominal fat tissue. This body habitus is associated with systemic inflammation and oxidative stress which in turn affects cell metabolism and can accelerate cellular aging, possibly affecting autophagy, sirtuins, and telomere maintenance. The review concludes with the thesis that chronic stress-induced biochemical imbalance, the direct central effects and indirect effects from adiposity, promote leukocyte cellular aging, as shown in Figure 1. Although the figure shows linear relationships in a closed system for simplicity, cell aging is just one of many outcomes of stress, and likewise stress is just one of many factors affecting cell aging.

\section{B. METABOLIC MECHANISMS OF AGING}

\section{B.1. Aging, allostasis, and biochemical stressors}

Allostasis appears to be at the nexus between stress and aging. Allostasis describes how our normal regulatory physiological systems fluctuate within rather large operating ranges to match environmental demands. Allostasis creates 'stability through change' by changing our level of arousal to meet the current demands. ${ }^{7}$ At the systems level, hormones are one of the primary allostatic regulators. At the cellular level, there are many mechanisms that regulate the stress responses, all aiming at genome protection (See Section D).

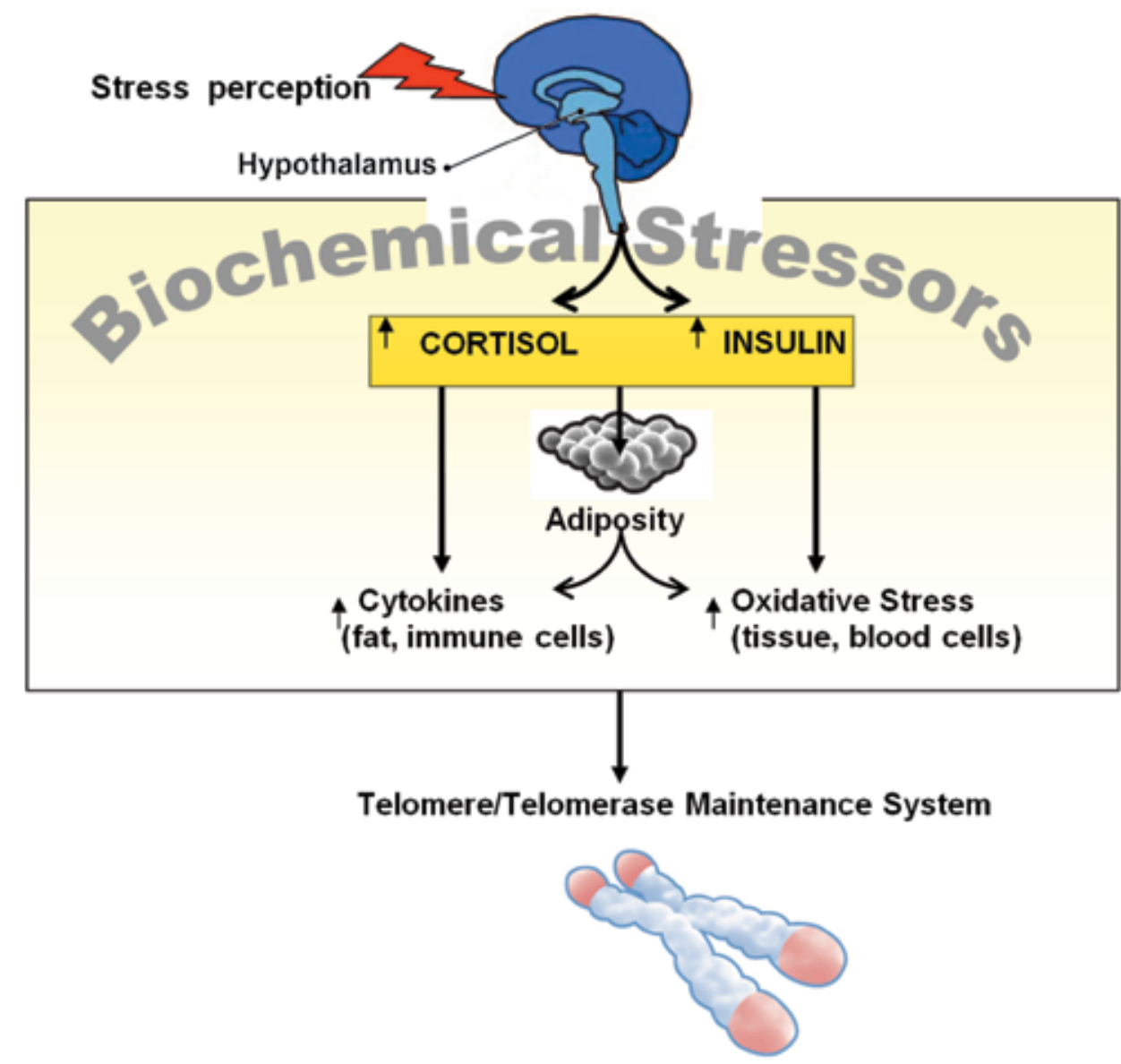

Figure 1. Some systemic and cellular effects of chronic stress 
Efficient allostasis describes facile adaptation, such as a quick peak stress response to mount energy to an acute stressor, and a rapid return to baseline, when the stressor terminates. Impaired allostasis is characterized by exaggerated reactivity peaks and sluggish recovery. ${ }^{4,8}$ Chronological aging impairs an organism's ability to sustain efficient allostasis when responding to different stressors. In humans, this is well-demonstrated by examining physiological regulation such as dynamic hypothalamic-pituitary-adrenal (HPA) axis responses or temperature changes. The cortisol response to stressors can be exaggerated in the elderly, and additionally, there is a sluggish negative feedback, so that cortisol stays elevated longer. ${ }^{910}$ Aging also causes a greater operating range of temperature, making the elderly more vulnerable to heat shock when under heat stress. Thus, impaired allostasis is inherent in chronological aging.

Chronic stress causes certain regulatory systems to have altered set points as well as changed response profiles. Aging is also associated with altered set points in multiple regulatory parameters such as cytokines, blood pressure, and lipids, and often deficiencies in androgens and IGF-1. An index of these markers is commonly used as a way to measure "allostatic load," the damage due to repeated fluctuations of the stress response. A high allostatic load index, indicating altered set points, has been linked to earlier mortality. ${ }^{11}$ Here we focus on four of these factors - cortisol and insulin, inflammatory factors, and oxidative stress-labeling these 'biochemical stressors'. These factors that are stress responsive become imbalanced during chronic stress, acting as physiological stressors which can accelerate cellular and tissue aging.

\section{B.2. The anabolic/catabolic hormonal balance}

Chronic stress tends to shift the hormonal balance toward low levels of the anabolic hormones that promote growth of lean and skeletal mass and prevent adiposity, such as androgens and IGF-1. It also can promote greater cortisol levels, or cortisol levels that are not well counter-regulated by anabolic hormones. This has been labeled anabolic/catabolic imbalance(A/C imbalance). ${ }^{12}$ In addition, cortisol increases insulin levels. ${ }^{13,14}$ Although insulin is anabolic and under normal basal conditions can increase both lean mass and fat mass, co-elevation of insulin with cortisol preferentially increases abdominal fat stores (See B2, below), making high insulin part of the $\mathrm{A} / \mathrm{C}$ imbalance profile.

Chronic stress can affect the hypothalamic pituitary adrenal axis in many ways. For example, it can lead to impaired negative feedback of the HPA axis, to slower recovery from stressors, and to either higher or lower cortisol levels. ${ }^{3,4}$ A considerable body of research has linked depression and chronic stress to elevated stress hormones, mainly cortisol and catecholamines, ${ }^{3,15-17}$ though not in all cases. ${ }^{18-20}$ While around $40 \%$ of depression is characterized by high cortisol levels, both depression and chronic stress have also been linked to hypocortisolemia or low Corticotropin-Releasing Hormone (CRH) ${ }^{21,22}$ In particular, atypical depression, states of chronic fatigue, and post-traumatic stress syndrome are linked to profiles of low cortisol and/or enhanced HPA axis negative feedback. ${ }^{21,23}$ It may be that a deficiency of cortisol contributes functionally to symptoms of inflammation and fatigue. Further, hypercortisolemic depression may actually promote functional hypocortisolemia, since glucocorticoid receptor sensitivity is low, which can lead to glucorticoid resistance and impaired signaling. ${ }^{24}$ Here we focus on effects of high cortisol, but acknowledge that low cortisol may have effects on cell aging through alternative pathways.

Anabolic hormones including androgens [Dehydroepiandrosterone (DHEA), and testosterone] and the somatotropic axis, mainly growth hormone (GH) and insulin like growth factor 1 (IGF-1), also play an important role in stress and aging. These hormones decrease with age and are often linked to poor metabolic health. It is notable that androgens appear to have gender specific effects on disease. Testosterone, and in some cases DHEA-S, predict lower incidence of diabetes and metabolic disease in men, but higher incidence in women. ${ }^{25-27}$

Like aging, chronic stress can lead to decreased IGF-1, GH, DHEA, and testosterone levels, ${ }^{12,28}$ although there are exceptions to this. ${ }^{29}$ As described elsewhere, chronic stress and obesity have independent and interactive effects on suppressing these hormones as well as disrupting the gonadal axis and reproductive function. ${ }^{30}$

DHEA often serves as an antiglucocorticoid and 
can buffer effects of inflammation and oxidative stress. ${ }^{31}$ Therefore, deficits in anabolic hormones may in some cases leave actions of cortisol unopposed. Anabolic hormones at sufficient levels signify restorative processes, while deficits may indicate earlier aging and risk of mortality. For example, A/C imbalance is related to cachexia, and earlier mortality from Chronic Heart Failure (CHF) ${ }^{32,33}$ Low levels of testosterone predicted mortality in male veterans. ${ }^{34}$ Another study examined whether low levels of IGF-1, testosterone, and DHEA were related to earlier mortality in men, while adjusting for various behavioral factors as well as presence of chronic diseases. They found that being low on all three of these hormones was related to a 2.5 times higher risk of early mortality. ${ }^{35}$

GH and IGF-1 decrease with aging, a phenomenon associated with muscle atrophy, but anabolic hormones, also promote malignancy such as breast cancer. ${ }^{36}$ People with low levels of GH have increased adiposity, insulin resistance, and increased incidence of cardiovascular disease, but nevertheless have very low rates of cancer. ${ }^{37}$ Thus, growth factors are doubleedged swords: they have favorable effects on musculoskeletal and thus metabolic health, yet increase the risk of cancers. Despite these links between GH/IGF-1 and good metabolic health in humans, GH/IGF hormones are linked to shorter lifespan in most lower species and mammalian models. ${ }^{38} \mathrm{New}$ research on genetic variation of genes controlling the IGF-1/GH signaling pathway, such as the FOXO gene, support the animal studies showing that mutations in these signaling pathways are linked to longevity in humans as well, ${ }^{39}$ painting a complex picture of the role of these growth hormones in human health.

\section{B.3. Insulin resistance and adiposity}

Chronological age is strongly associated with increases in insulin resistance and adiposity, and it is becoming clear that long time exposure to insulin resistance accelerates biological aging. For example, in diabetes, there is early onset of certain diseases of aging, such as dementia, as well as signs of general body aging such as frailty. ${ }^{40}$

Chronic stress may accelerate these age related metabolic changes. Stress is related to obesity, especially abdominal obesity, and insulin resistance in both animal and human models. ${ }^{41-45}$ For example, psychological stress, including job stress, is associated with abdominal fat in cross-sectional ${ }^{46}$ and prospective studies. ${ }^{47-49}$

These relationships are not surprising, as abdominal fat is an ideal target tissue for stress. Abdominal fat is regulated in part by $\mathrm{A} / \mathrm{C}$ balance. Low levels of androgens and high levels of cortisol and insulin promote abdominal fat deposition. ${ }^{50}$ Visceral fat is well equipped to respond to the stress-induced combination of high cortisol and high insulin. For one, it has a greater density of glucocorticoid receptors. ${ }^{51,52}$ Secondly, insulin promotes lipoprotein lipase, the fat storing enzyme that converts triglycerides into stored fat (free fatty acids), and cortisol promotes prolonged elevations of lipoprotein lipase. ${ }^{53}$ Rodent studies have shown that the combination of stress plus high fat diet leads to greater abdominal fat storage than either stress or high fat diet alone. ${ }^{54}$

In turn, abdominal fat contributes to numerous biochemical stressors. Clinically, greater abdominal fat thickness is associated with higher levels of systemic total oxidative stress (lower antioxidants, higher lipid markers ${ }^{56}$ and greater number of inflammatory markers. ${ }^{57}$ Fat cells, both subcutaneous, abdominal and particularly visceral abdominal fat, release cytokines such as TNF-a and IL-6. ${ }^{58}$ Monocytes infiltrate the fat, especially near dead cells, and further release cytokines, promoting systemic inflammation. Animals with fat transplants of visceral but not subcutaneous origin develop increased inflammatory and cardiovascular disease, suggesting that the inflammation alone is pathogenic. ${ }^{55}$ Thus, the visceral fat tissue is a likely source of the chemicals that induce cellular aging.

\section{B.4. Oxidative stress}

Production of free radicals (oxidative stress) is thought to exert a major influence on cell aging and tissue damage, ${ }^{59,60}$ particularly to cardiac cells and the brain. ${ }^{61}$ Free radicals tend to increase with age, as indexed by markers such as lipid peroxidation and impaired antioxidant activity. However, in elderly individuals who are still healthy, oxidative stress level can be similar to that of young adults, ${ }^{62}$ or at least comparable to antioxidant defenses, ${ }^{63}$ suggesting that oxidation is not inevitable in aging. It appears that psychological stress and lifestyle factors such as 
smoking and sedentariness have an impact on the level of oxidation. ${ }^{64,65}$ Oxidation in turn is associated with functional decline and might be partly responsible for whole body accelerated aging. In an elderly population (>80 years old), free radicals were associated with poorer cognitive function, loss of autonomy, loss of ability to perform daily activities, and institutionalization, as well as depressive symptoms. ${ }^{66}$

Oxidative stress appears to play an especially important role in the brain. A/C imbalance may affect free radical production and neurodegenerative diseases. Cortisol is essential for brain viability. However, when it is too high for too long, certain vulnerable neurons may be damaged, in part by increases in oxidative stress. ${ }^{67,68}$ DHEA and estrogens can prevent oxidative stress damage in neurons. ${ }^{69-71}$ DHEA can block cortisol-mediated excitatory neurotoxicity, pointing to the likely importance of the balance between cortisol and DHEA. ${ }^{71}$

There are a growing number of studies both in rats $^{72}$ and in humans $s^{73-76}$ that have found links between markers of oxidative stress and psychological distress. Markers of oxidative stress are increased by acute stress exposure ${ }^{77,78}$ as well as by chronic states, such as major depression ${ }^{79}$ and duration of exposure to caregiving. ${ }^{76}$ In one study of acute stress, individuals who responded with higher ratings of anger and tendency to suppress anger had greater reactive oxygen species 30 minutes after the acute stressor. ${ }^{77}$ However, other studies found that acute stress may reduce markers of oxidation. It may be that both the state of a person's health and antioxidant defenses together determine whether acute stress leads to increases or decreases in net oxidation.

The links between psychological stress and blood levels of oxidative stress may be mediated in part by increases in cortisol and insulin, although there is no direct evidence of this at present. Elevations of glucose and insulin from chronic stress may promote free radical production through auto-oxidative glycosylation and through insulin-mediated sympathetic activity. ${ }^{80}$

\section{HEALTH BEHAVIORS}

C.1. Health Behaviors are important contributors to $\mathrm{A} / \mathrm{C}$ imbalance and other biochemical stressors. Health behaviors including activity, diet, and sleep shape our hormonal milieu. Sedentariness, a high fat diet, and insufficient sleep have been associated with higher HPA axis and/or lower GH axis responsiveness and higher insulin levels. ${ }^{81-83}$ Lifestyle factors have also been linked to DNA damage due to oxidation. For example, smoking, alcohol, and a high fat diet are associated with greater oxidative stress. ${ }^{64}$

C.2. Eating behavior has highly significant effects on biochemical stressors (oxidative stress and inflammation). Overeating can lead to increased aerobic metabolism and thus overproduction of free radicals and increased fat storage. Excess adiposity in turn can lead to decreased insulin sensitivity. An excess glucose infusion, possibly analogous to a binge episode of overfeeding, led to a decrease in antioxidants, increase in liver oxidative stress, and systemic inflammatory response. ${ }^{84}$ In a rat model of metabolic syndrome, high fat and sugar feeding leads to greater oxidative stress, ${ }^{84,85}$ apparently through upregulation of NAD(P)H oxidase in kidney and cardiovascular tissue, and downregulation of antioxidants. Dietary fat can decrease the activity of PPAR- $\gamma$, which has anti-inflammatory action. PPAR- $\gamma$ inhibits proinflammatory cytokines in monocytes, partly through inhibition of nuclear factor kappa B (NFkB). In one study of patients with metabolic syndrome, exposure to dietary fat overload led to lower expression of PPAR- $\gamma$, and such decreases in turn were correlated with greater oxidative stress. ${ }^{86}$ In another study in rodents, a thiozolidinedione, an agonist of PPAR$\gamma$, used to increase insulin sensitivity, also reduced oxidative stress (and visceral fat). ${ }^{84}$ Caloric restriction can also reduce oxidative stress, as described below (Section F.2).

While actual caloric restriction has many positive effects on biochemical milieu, self reports of cognitive dietary restraint (trying to restrict calories, but not necessarily doing so) appear to show different or even opposite relations. Dietary restraint, especially in combination with a strong tendency to overeat, is related to higher cortisol levels ${ }^{87}$ and, in some studies, to perceived stress. ${ }^{88}$ Restraint is also related to shorter leukocyte telomeres, independent of body mass index. ${ }^{89}$ The association could be due to a myriad of 
factors related to restraint. We speculate that restraint might be a proxy factor for greater exposure to both psychological and metabolic stress, including high cortisol and bouts of caloric restriction, followed by overeating and the ensuing biochemical stress described above. ${ }^{89}$

Many studies try to covary out health behaviors to examine pure effects of stress arousal. However, stress works both directly and also through behavioral pathways. Chronic stress serves as an organizing factor, shaping most daily self-care behaviors and sleep. For example, chronic stress or cortisol exposure motivates people to select high fat food and to overeat. ${ }^{90,91}$ Chronic stress impairs sleep, and short duration sleep is a predictor of weight gain. ${ }^{92}$ Thus, while it is helpful to examine 'unique' effects of chronic stress on physiology, the phenotypic effects inherently include several of these behavioral pathways. In the next section we review how stress induced biochemical changes may be related to several cell aging mechanisms.

\section{CELL AGING MECHANISMS}

\section{D.1. The Telomere/Telomerase Maintenance System}

The telomere/telomerase maintenance system, discovered by Elizabeth Blackburn, Carol Greider, and colleagues, offers insight into how cells age and senesce and, as recent research suggests, how people grow 'old' biologically. Telomeres are the protective nucleoprotein structures capping the ends of eukaryotic chromosomes, consisting of a simple repeat sequence (TTAGGG). Telomeres naturally shorten with mitosis. With every cell division, a portion of the telomeric DNA may not be replicated due to the "end replication problem" - that is, DNA polymerase does not work properly at the end of a DNA strand. ${ }^{93}$ Thus, older mitotic cells tend to have shorter TL than younger cells. TL shortening is not merely a marker of cellular aging but also a mechanism, with important functional consequences. Mitotic cells can undergo a limited number of cell divisions before they become senescent and lose the ability to grow and divide, unless there are other conditions, such as high telomerase, as explained below. Telomere shortening is a mechanism for the development of this cellular senescence. Short TL leads to genomic instability, end-to-end chromosome fusion, less efficient mitosis, and loss of ability for cell replenishment. ${ }^{94-96}$

Telomerase provides enzymatic maintenance of TL and can counteract shortening and its functional consequences. Telomerase is a ribonucleoprotein reverse transcriptase cellular enzyme that adds telomeric DNA to shortened telomeres. If the TL shortening represents the clock ticking forward on the cells limited lifespan, telomerase can reverse or slow this clock. ${ }^{97}$ Short TL stimulates telomerase, and cells with short TL can be stable with sufficient telomerase. Thus, TL and telomerase form an intricately interdependent dynamic system. Telomerase may also have independent effects on organismic health by, for example, promoting cell longevity even in the face of critically shortened telomeres. ${ }^{97}$

Shortened telomeres are linked to age-related disease and mortality. Shorter TL is associated with $\mathrm{CVD}^{98,99}$ and risk factors including pulse pressure, ${ }^{100-102}$ obesity, ${ }^{104}$ insulin resistance, ${ }^{103}$ and diabetes. ${ }^{104-106}$ Shorter TL predicts mortality in non-clinical samples, ${ }^{107,108}$ as well as in samples with chronic kidney disease, ${ }^{109}$ Alzheimer's, ${ }^{110}$ and stroke. ${ }^{111}$

\section{D.2. Biochemical stressors affect the Telomere/ Telomerase maintenance system}

Stress arousal appears to be linked to telomerase and TL maintenance. Two studies have examined stress hormones, finding that cortisol is associated with shorter TL in vivo ${ }^{112}$ and that exposure to cortisol dampens telomerase activity in vitro. ${ }^{113}$ Markers of inflammation are linked to TL shortening in several studies. Shorter TL length has been related to higher IL-6 and CRP in hemodialysis patients, ${ }^{109}$ and in men. ${ }^{108}$ Certain inflammatory factors can lead to $\mathrm{T}$ cell turnover, and possible TL shortening, if in the presence of low telomerase.

Oxidative stress clearly exerts a negative influence on TL maintenance. It can dramatically decrease TERT (telomerase protein) activity ${ }^{114,115}$ and can damage telomeric DNA much more than non-telomeric chromosomal DNA of fibroblasts in vitro. ${ }^{116}$ Conversely, addition of antioxidants decelerates TL shortening in cultured cells ${ }^{117}$ and prolongs telomer- 
ase activity. ${ }^{118}$ Cross-sectional research in humans is consistent with the concept that oxidative stress may have cumulative effects on TL length. We found that oxidative stress imbalance (ratio of oxidative stress to antioxidants) in vivo is associated with shorter TL length, ${ }^{76}$ and others have now found similar associations using various markers of oxidative stress. ${ }^{119-121}$

\section{Insulin Resistance and adiposity}

TL length is related to many factors associated with overeating, among them excess adiposity, insulin resistance, and increased leptin levels. ${ }^{104}$ In one study, an increase in obesity over ten years was associated with a decrease in TL length. ${ }^{103}$ Multivariate modeling suggested that this was due to insulin resistance. Similarly, another study found that hypertension was associated with shorter TL, also accounted for by insulin resistance. ${ }^{121}$ A recent cross-sectional study found the longest TL in healthy controls, and progressively shorter TL length in people with impaired glucose tolerance and diabetes without plaques, and the shortest in those with diabetes and plaques. ${ }^{120}$ Another study found that within diabetics, oxidative stress and not inflammation was correlated with monocyte TL length. Most participants were taking statins, which can reduce inflammation and might explain the null finding with inflammation. ${ }^{106}$

Thus, one can speculate that chronic caloric excess may be an early proximal promoter of accelerated aging through its effects at the systems level on body composition and insulin sensitivity, and at the cellular level through affecting the telomere/telomerase maintenance system.

\section{D.3. Additional putative pathways of psychological stress that affect cell aging}

\section{Stress resistance}

Although no studies have examined effects of psychological stress on cell aging mechanisms, there is a solid body of research examining effects of physiological stressors. Excessive exposure to physiological stressors can cause damage to molecules, necessitating the mobilization of cell repair mechanisms, promotion of housekeeping activities, and recovery from the stressor. ${ }^{122}$ When these protective functions are overwhelmed, damage ensues. Several examples of stress and damage were reviewed above, such as the effect of oxidative stress on TL shortening. ${ }^{123}$

However, more intriguing than stress-induced damage is stress induced resistance. Small doses of physiological stressors can promote longer living cells. Short-term manageable stressors can promote "hormesis" or a toughening of the cell. ${ }^{124}$ All organisms from c. elegans to humans have intracellular stress responses that increase when exposed to stressors and that protect them from physiological stressors such as heat and ultraviolet radiation. These protective responses to stress have been labeled 'stress resistance.' This includes energy metabolism, heat shock proteins, DNA repair enzymes, and free radical scavengers. ${ }^{125,126}$ These are crucial for cell and organism survival. For example, heat stress can denature proteins and cause them to aggregate. Heat shock proteins serve as molecular chaperones for the damaged molecules.

Stress resistance is affected by both the dose of the stressor and cell's age and is thought to be a major pathway promoting cell longevity. ${ }^{127}$ For example, mild heat treatments early in life produce greater heat shock proteins and longevity in c. elegans. ${ }^{128}$

Stress resistance appears to involve energy regulating and growth signaling pathways. Old cells cannot generate energy as efficiently, possibly due to aged mitochondria. Aging impacts the ability to respond to stressors. Cells of older people have poorer response to physiological stressors, ${ }^{129}$ including lower heat shock protein response. In one study, immune cells from an elderly sample exposed to paraquat had an $8 \%$ mean increase in antioxidant response (superoxide dismutase or SOD), whereas those under 40 years had an $80 \%$ response. Of the almost $50 \%$ who died five years later, all showed a low SOD response to stress. ${ }^{130}$ Even though this was a small sample, it demonstrates the effect of chronological aging on stress resistance and offers a link between resistance and longevity in humans.

Activity of the somatotropic axis is also related to stress resistance. Cells (fibroblasts) from long-lived animals, such as the Snell mice which have low IGF, show stress resistance to injuries from oxidative stressors. Long-lived mutant worms, which have low activity 
in the insulin/IGF signaling pathway, have greater stress resistance to heat stress and oxidative stress. ${ }^{124}$ Stress resistance is a common characteristic of certain long-lived mutant animals, ${ }^{131}$ although in several cases mechanisms promoting stress resistance can be uncoupled from those promoting longevity. ${ }^{132}$

\section{Biochemical stressors are linked to other cell aging mechanisms}

There are several cell aging processes that are particularly affected by excess energy balance-among them systemic over-exposure to glucose and insulin. Excess glucose is a key factor that is pro-aging through both direct and indirect effects of insulin exposure. ${ }^{133}$ There are numerous ways in which excess glucose and insulin can lead to cellular aging, as reviewed by Kassi et al. ${ }^{133}$ For example, glucose and increased glycolysis can decrease sirtuins and autophagy.

Sirtuins, protein deacetylases, are important for stabilizing DNA and for longevity. They appear to reduce inflammation and oxidative stress, to promote stress resistance, ${ }^{134}$ and may promote stability of the telomere. ${ }^{135}$ No studies have examined whether stress mediators such as cortisol and catecholamines affect expression of sirtuins.

Autophagy, the breaking down and recycling of damaged molecules, is an important housekeeping function of the cell. It thus allows cells to adapt to their changing environment and might be thought of as a key player in allostasis of the cell. Autophagy, or 'self-eating', occurs by enzymatic degradation of intracellular 'garbage.' Autophagy becomes impaired with aging, and low levels of autophagy are related to cancer and neurodegenerative diseases. ${ }^{136}$ Systemic regulators of autophagy are not well studied. However, caloric restriction promotes autophagy, which in turn is required for the caloric restriction-induced longevity in c. elegans. ${ }^{137}$ Insulin may also regulate rate of autophagy. High levels of circulating insulin can impair autophagy in the kidney, ${ }^{138}$ whereas decreased insulin receptor signaling promotes autophagy. ${ }^{139} \mathrm{Sev}$ eral studies suggest that acute exposure to stressors or glucocorticoids appears to increase autophagy, but no studies have examined the effects of chronic stress exposure. ${ }^{140,141}$

\section{E. INDIVIDUAL DIFFERENCES: WHO WILL SUFFER ACCELERATED AGING FROM CHRONIC STRESS EXPOSURE?}

We have discussed chronic stressors as relevant triggers of a stress cascade of cellular aging, focusing on leukocyte TL. Stressors can lead to a wide range of emotional responses, such as anger, fear, or sadness and withdrawal, and each of these likely has their own physiological profiles. Individual temperament and these distinct emotional responses to chronic stressors will influence the stress signatures-the type of stress responses and potential dysregulation that one encounters. Therefore, it is important not only to identify groups at greatest risk of exposure to chronic stressors but also to phenotype who within these groups are most vulnerable to the stress cascade. Thus, we briefly define the psychological stress response that appears to be most relevant to our model. In this model, the typical chronic stress response is characterized by exaggerated levels of high cortisol and high insulin.

Who is at most risk of this type of stress response? In animal studies, anxiety proneness is linked to greater reactivity, which in turn is linked to aging. For example, in rats, freezing or slower maze performance predicts a premature aging syndrome, cognitive decline, lower antioxidants, and higher oxidative stress. ${ }^{142,143}$ Further, greater behavioral reactivity or arousal is linked to shorter lifespan. ${ }^{143}$ From an evolutionary perspective, anxiety prone individuals, those who tend to vigilantly monitor the environment, should do well in times of acute stress, but when exposed to chronic stress, the common condition in modern society, she or he will suffer from greater levels of allostatic load than other types of responders, such as those responding with anger rather than fear and anxiety. ${ }^{144}$

While there is no 'one to one' mapping of personality onto stress response, in general, the exaggerated cortisol response appears to be most typical of people with a cognitive style characteristic of greater trait anxiety. Below we discuss several key traits related to anxiety, specifically greater social inhibition and vulnerability to social evaluative threat. Social evaluative threats elicit strong cortisol response. ${ }^{145}$ People with 
a more inhibited personality type, characterized by anxiety or low self-esteem, are prone to high cortisol reactivity or lack of cortisol habituation over time ${ }^{146}$ and have higher activation in their amygdala in response to novel or stressful stimuli. ${ }^{147,148}$ Many studies have found that people with the 'distressed' personality-characterized by negative affect/neuroticism and social inhibition (suppressing expression of negative feelings) - tend to have greater proinflammatory cytokines as well as increased cardiovascular morbidity and mortality. ${ }^{149,150}$ In the first study examining a personality trait and telomere length, O'Donovan et al found that pessimism, the tendency to expect negative outcomes in the future, was related to shorter telomere length, as well as greater IL- $6 .{ }^{151}$

Social and genetic contexts will also affect relationships between personality and stress related aging. Those with high social support tended to show lower cortisol reactivity and neural threat responses to a social evaluative stressor. ${ }^{152}$ People with the short allele of the serotonin transporter, which is related to higher neuroticism, and exposure to greater life stress, tend to have higher activity in the amygdala during a resting baseline when their mind is not occupied by tasks. ${ }^{153}$ It is likely that personality marked by stress vulnerability or stressor exposure alone will only be weakly predictive of stress related aging. Rather, geneenvironment interactions will be important to predict meaningful variance in stress-induced aging.

\section{F. INTERVENTIONS: CAN WE REVERSE OR AMELIORATE METABOLIC AGING?}

Can interventions improve biochemical stressors? This question has been addressed in many types of studies so far, including pharmacological, psychological/behavioral, and caloric restriction studies. Improved $\mathrm{A} / \mathrm{C}$ balance (decreased in cortisol, insulin, and increased in DHEA) can be partly achieved by behavioral interventions that work directly on stress and metabolic pathways, targeting neural regulation of these pathways.

\section{F.1. Psychological/Behavioral interventions}

By reducing perceptions of stress and increasing healthy behaviors, we may promote subtle but important improvements in $\mathrm{A} / \mathrm{C}$ balance, reducing cortisol and increasing anabolic hormones, vagal tone, and other restorative processes. Furthermore, by restoring hormonal balance naturally, through increasing endogenous secretion (vs. pharmacologically), one preserves the secretory patterns and diurnal rhythms (vs. a bolus at one time of day, as in most pharmacological approaches). These changes in hormonal milieu may in turn slow cell aging processes.

Interventions that include health behavior change in addition to psychosocial support or coping skills are likely to be more effective in improving health than targeting only one behavior. Increasing fitness is likely one of the most potent interventions for restoring $\mathrm{A} / \mathrm{C}$ balance and can improve well-being. Long-term exercise can decrease cortisol and increase DHEA, $\mathrm{GH}$, and IGF-1, ${ }^{154}$ and is associated with reduced cortisol reactivity ${ }^{155}$ and cardiovascular reactivity to acute stress, ${ }^{156}$ as well as reduced anxiety ${ }^{157}$ and depressive symptoms. ${ }^{158}$

Psychosocial interventions have been effective in improving $\mathrm{A} / \mathrm{C}$ balance. ${ }^{159}$ For example, an enrichment program for elderly subjects ${ }^{160}$ increased DHEA, testosterone, estradiol, and GH levels, as well as significantly attenuating decreases in height, likely indicating less bone loss. In addition, Cruess and colleagues have shown that a cognitive behavioral stress management, designed to reduce stress appraisals and depressive symptoms, can improve $\mathrm{A} / \mathrm{C}$ balance by reducing cortisol and catecholamines and by increasing DHEA and testosterone. ${ }^{161}$ A yoga intervention for women with breast cancer appeared to slightly attenuate the post-radiation damage to DNA, compared to a control group of women receiving supportive counseling. ${ }^{162}$

Nutritional interventions are a potent way to improve biochemical milieu and possibly cellular aging. A low fat diet for type 2 diabetics can reduce adiposity, insulin resistance, oxidative stress, and inflammatory factors. ${ }^{163}$ Combining improved diet with stress reduction and activity may provide the most potent interventions for healthy aging. A preliminary intervention study of intensive lifestyle modification across these domains found significant increases in telomerase. ${ }^{164}$ Currently, our research group at UCSF is developing interventions that focus on reducing metabolic and stress arousal pathways (including mindful eating 
behavior, improved nutrition, activity, and stress reduction). However, one limitation to most behavioral interventions is poor long-term maintenance of behavioral changes, such as low compliance with effective doses of daily meditation, healthy diet and activity. The biochemical changes reviewed may last only as long as there is sufficient maintenance of the behavioral and psychological changes.

\section{F.2. Caloric Restriction}

Caloric Restriction is one of the most reliable manipulations to increase lifespan across species, and the complex mechanisms are reviewed elsewhere. ${ }^{165,166}$ Caloric restriction appears to decrease metabolic rate, free radical generation, adiposity, and sympathetic activity and may reduce insulin and increase insulin sensitivity and DHEA-S levels. ${ }^{167,168}$ It is thought that caloric restriction increases longevity in part through suppressing expression of sirtuins which then indirectly suppress fat mobilization (through suppressing PPAR- $\gamma) .{ }^{169}$

Thus, caloric restriction appears to reduce biochemical stressors and the stress cascade described in Figure 1, with one important exception. It is notable that it appears to increase cortisol, despite having overwhelmingly positive effects on health. No studies have yet examined whether caloric restriction actually increases telomerase activity or TL length.

\section{SUMMARY}

There is now a large body of support for metabolic changes during psychological stress, toward energy storage in abdominal fat depots, and away from restorative activities of the anabolic hormones. ${ }^{170}$ Although there are few studies examining psychological stress and cell aging, Figure 1 proposes the hypothesis that stress related biochemical factors (hormones, inflammatory factors, and oxidative stress) may promote cellular aging, particularly by dampening telomerase and leading to earlier cell senescence. Like chronic stress, abdominal obesity may systemically affect cell aging through a similar cascade of biochemical stressors-mainly insulin and glucose, and inflammation from fat tissue. Together, stress and obesity could powerfully fuel a state of biochemical stress and thus be a recipe or pathway for accelerated cell aging.
Given the preponderance of psychological stress and its effects on food consumption and abdominal obesity, a better understanding of the interaction between stress and obesity may offer ways of preventing the biochemical stressor cascade.

Several studies have linked the systemic changes in hormonal balance and adiposity with cell aging. Most of these studies have been correlational clinical studies and do not demonstrate causal pathways. More mechanistic studies, using animal and in vitro models, need to be performed in order to test whether these correlations represent causal relationships. Given that the systemic responses of the nervous system are regulated by psychological appraisal processes, the prefrontal cortex and limbic system, psychological stress resistance must also be considered a key determinant of stress arousal, physiological stress resistance, and thus rate of cell aging. Impaired allostasis and impaired stress resistance seem inherent in most chronological aging. This raises the question of whether enhanced allostasis - the efficient response to stressors characteristic of youthful systems - is protective of biological aging and promotes longevity. More clinical studies are warranted to test whether decreases in psychological stress and increases in cellular stress resistance and neuroendocrine patterns of enhanced allostasis can indeed increase telomerase activity and telomere maintenance.

Acknowledgments to Dr.'s Owen Wolkowitz and Robert Lustig for their helpful input, to the 2007 Hormones and Longevity meeting, and to The National Institute of Mental Health K08MH64110-01A1 and NARSAD Young Investigator Award.

\section{REFERENCES}

1. Wan H, Sengupta M, Velkoff VA, DeBarros KA, 2005 $65+$ in the United States. US Census Bureau [http://www. census.gov/prod/2006pubs/p23-209.pdf. Accessed.

2. Bosma H, Stansfeld SA, Marmot MG, Peter R, Siegrist J, Marmot M, 1998 Job control, personal characteristics, and heart disease: Two alternative job stress models and the risk of coronary heart disease. J Occup Health Psychol 3: 402-409.

3. Chrousos G, Gold P, 1992 The concepts of stress and stress system disorders. JAMA 267: 1244-1252.

4. McEwen B, 1998 Protective and damaging effects of stress mediators. New England Journal of Medicine 338: 
171-179.

5. Musselman D, Evans D, Nemeroff C, 1998 The relationship of depression to cardiovascular disease: epidemiology, biology, and treatment. Arch Gen Psychiatry 55: 580-592.

6. Stansfeld SA, Fuhrer R, Shipley MJ, Marmot MG, 2002 Psychological distress as a risk factor for coronary heart disease in the Whitehall II Study. Int J Epidemiol 31: 248-255.

7. Sterling P, Eyer J, 1988 Allostasis: A new paradigm to explain arousal pathology. In: Fisher S, Reason J, eds. Handbook of Life Stress: Cognition and Health: John Wiley \& Sons, Ltd; pp,629-649.

8. Bower J, Low C, Moskowitz J, Sepah S, Epel E, 2008 Pathways from benefit finding to physical health: Enhanced psychological and physiological responses to stress. Social and Personality Psychology Compass; in press.

9. Seeman T, Robbins R, 1994 Aging and hypothalamicpituitary-adrenal response to challenge in humans. Endocr Rev 15: 233-259.

10. Otte C, Hart S, Neylan TC, Marmar CR, Yaffe K, Mohr DC, 2005 A meta-analysis of cortisol response to challenge in human aging: importance of gender. Psychoneuroendocrinology 30: 80-91.

11. Seeman T, Singer B, Rowe J, McEwen B, 2001 Allostatic load as a marker of cumulative biological risk: MacArthur studies of successful aging. Proc Natl Acad Sci USA 98: 4770-4775.

12. Epel E, Burke H, Wolkowitz O 2007 Psychoneuroendocrinology of Aging: Focus on anabolic and catabolic hormones. In: Aldwin C, Spiro A, Park C, eds. Handbook of Health Psychology of Aging: Guildford Press; pp, 119-141.

13. Dallman MF, la Fleur SE, Pecoraro NC, Gomez F, Houshyar H, Akana SF, 2004 Mini review: glucocorticoids--food intake, abdominal obesity, and wealthy nations in 2004. Endocrinology 145: 2633-2638.

14. Strack A, Sebastian R, Schwartz M, Dallman M, 1995 Glucocorticoids and insulin: reciprocal signals for energy balance. Am J Physiol 268:R142-R149.

15. Melamed S, Ugarten U, Shirom A, Kahana L, Lerman Y, Froom P, 1999 Chronic burnout, somatic arousal, and elevated salivary cortisol levels. J Psychosom Res 46: 591-598.

16. Steptoe A, Cropley M, Griffith J, Kirschbaum C, 2000 Job strain and anger expression predict early morning elevations in salivary cortisol. Psychosom Med 62: 286292.

17. Vedhara K, Cox N, Wilcock G, et al, 1999 Chronic stress in elderly carers of dementia patients and antibody response to influenza vaccination. The Lancet 353: 627-631.

18. Burton F, Hinton J, Neilson E, Beastall G, 1996 Concentrations of sodium, potassium and cortisol in saliva, and self-reported chronic work stress factors.Biol Psycho 142: 425-438.
19. Irwin M, Hauger R, Patterson T, Semple S, Ziegler M, Grant I, 1997 Alzheimer caregiver stress: basal natural killer cell activity, pituitary adrenal cortical function, and sympathetic tone. Ann Behav Med 1997: 83-90.

20. Pike J, Smith T, Hauger R, et al, 1997 Chronic life stress alters sympathetic, neuroendocrine, and immune responsivity to an acute psychological stressor in humans. Psychosom Med 59: 447-457.

21. Gold PW, Chrousos GP, 2002 Organization of the stress system and its dysregulation in melancholic and atypical depression: high vs low CRH/NE states. Mol Psychiatry 7: 254-275.

22. Fries E, Hesse J, Hellhammer J, Hellhammer DH, 2005 A new view on hypocortisolism. Psychoneuroendocrinology 30: 1010-1016.

23. Bower J, Ganz P, Aziz N, 2007 Altered cortisol response to psychologic stress in breast cancer survivors with persistent fatigue. Psychosom Med 67:277-280.

24. Raison CL, Miller AH, 2003 When not enough is too much: the role of insufficient glucocorticoid signaling in the pathophysiology of stress-related disorders. Am J Psychiatry 160: 1554-1565.

25. Ding EL, Song Y, Malik VS, Liu S, 2006 Sex differences of endogenous sex hormones and risk of type 2 diabetes: a systematic review and meta-analysis. JAMA 295: 12881299.

26. Barrett-Connor E, Ferrara A, 1996 DHEA, DHEAS, obesity, WHR, and NIDDM in postmenopausal women: The Rancho Bernardo Study. J Clin Endocrinol Metab 81: 5-64.

27. Dandona P, Dhindsa S, Chaudhuri A, Bhatia V, Topiwala S, Mohanty P, 2008 Hypogonadotrophic hypogonadism in type 2 diabetes, obesity and the metabolic syndrome. Curr Mol Med 8: 816-828.

28. Morrison M, 1996 Hormones, Gender and the Aging Brain: The Endocrine Basis of Geriatric Psychiatry: Cambridge University Press.

29. Heuser I, Deuschle M, Luppa P, Schweiger U, Standhardt H, Weber B, 1998 Increased diurnal plasma concentrations of dehydroepiandrosterone in depressed patients. J Clin Endocrinol Metab 83: 3130-3133.

30. Kyrou I, Tsigos C, 2008 Chronic stress, visceral obesity and gonadal dysfunction. Hormones (Athens) 7: 287293.

31. Maninger N, Wolkowitz OM, Epel ES, Reus V, Mellon S, 2008 Neurobiological and Neuropsychiatric Effects of Dehydroepiandrosterone (DHEA) and DHEA Sulfate (DHEAS). Front Neuroendocrinol 30: 65-91.

32. Anker SD, Chua TP, Ponikowski P, et al, 1997 Hormonal changes and catabolic/anabolic imbalance in chronic heart failure and their importance for cardiac cachexia. Circulation 96: 526-534.

33. Jankowska EA, Biel B, Majda J, et al, 2006 Anabolic deficiency in men with chronic heart failure: prevalence and detrimental impact on survival. Circulation 114: 1829-1837. 
34. Shores MM, Matsumoto AM, Sloan KL, Kivlahan DR, 2006 Low serum testosterone and mortality in male veterans. Arch Intern Med 166: 1660-1665.

35. Maggio M, Lauretani F, Ceda GP, et al, 2007 Relationship between low levels of anabolic hormones and 6-year mortality in older men: the aging in the Chianti Area (InCHIANTI) study. Arch Intern Med 167: 22492254.

36. Hankinson SE, Willett WC, Colditz GA, et al, 1998 Circulating concentrations of insulin-like growth factor-I and risk of breast cancer. Lancet 351: 1393-1396.

37. Laron Z, 2008 The GH-IGF1 axis and longevity. The paradigm of IGF1 deficiency. Hormones (Athens) 7: 24-27.

38. Berryman DE, Christiansen JS, Johannsson G, Thorner MO, Kopchick JJ, 2008 Role of the GH/IGF-1 axis in lifespan and healthspan: Lessons from animal models. Growth Horm IGF Res 18: 455-471.

39. Willcox BJ, Donlon TA, He Q, et al,, 2008, FOXO3A genotype is strongly associated with human longevity. Proc Natl Acad Sci USA 105: 13987-13992.

40. Morley J, 2008 Diabetes and aging: epidemiologic overview. Clin Geriatr Med 24: 395-405.

41. Bjorntorp P, Rosmond R, 1999 Hypothalamic origin of the metabolic syndrome. The Metabolic Syndrome. Vol 892. New York, NY: Annals of the New York Academy of Sciences.

42. Brindley D, Rolland Y, 1989 Possible connections between stress, diabetes, obesity, hypertension and altered lipoprotein metabolism that may result in atherosclerosis. Clin Sci 77: 453-461.

43. Dallman MF, Pecoraro NC, la Fleur SE, 2005 Chronic stress and comfort foods: self-medication and abdominal obesity. Brain Behav Immun 19: 275-280.

44. Epel E, McEwen B, Seeman T, et al, 2000 Stress and body shape: Consistently greater stress-induced cortisol reactivity among women with abdominal fat. Psychosom Med 62: 623-632.

45. Rosmond R, Lapidus L, Marin P, Bjorntorp P, 1996 Mental distress, obesity, and body fat distribution in middle-aged men. Obes Res 4: 245-252.

46. Kouvonen A, Kivimaki M, Cox SJ, Cox T, Vahtera J, 2005 Relationship between work stress and body mass index among 45,810 female and male employees. Psychosom Med 67: 577-583.

47. Kivimaki M, Head J, Ferrie JE, et al, 2006 Work stress, weight gain and weight loss: evidence for bidirectional effects of job strain on body mass index in the Whitehall II study. Int J Obes (Lond) 30: 982-987.

48. Korkeila M, Kaprio J, Rissanen A, Koshenvuo M, Sorensen TI, 1998 Predictors of major weight gain in adult Finns: stress, life satisfaction and personality traits. Int J Obes Relat Metab Disord 22: 949-957.

49. Brunner EJ, Chandola T, Marmot MG, 2007 Prospective effect of job strain on general and central obesity in the Whitehall II Study. Am J Epidemiol 165: 828-837.
50. Bjorntorp P, 1996 The regulation of adipose tissue distribution. Int J Obes Relat Metab Disord 20: 291-302.

51. Dallman M, Pecoraro N, Akana S, et al, 2003 Chronic stress and obesity: A new view of "comfort food." PNAS; 100:11696-11701.

52. Rebuffe-Scrive M, Walsh U, McEwen B, Rodin J, 1992 Effect of chronic stress and exogenous glucocorticoids on regional fat distribution and metabolism. Physiol Behav 52: 583-590.

53. Appel B, Fried SK, 1992 Effects of insulin and dexamethasone on lipoprotein lipase in human adipose tissue. Am J Physiol 262: E695-699.

54. Kuo LE, Kitlinska JB, Tilan JU, et al, 2007 Neuropeptide $\mathrm{Y}$ acts directly in the periphery on fat tissue and mediates stress-induced obesity and metabolic syndrome. Nat Med 13: 803-811.

55. Ohman MK, Shen Y, Obimba CI, et al, 2008 Visceral adipose tissue inflammation accelerates atherosclerosis in apolipoprotein E-deficient mice. Circulation 117: 798-805.

56. Palmieri VO, Grattagliano I, Portincasa P, Palasciano G, 2006 Systemic oxidative alterations are associated with visceral adiposity and liver steatosis in patients with metabolic syndrome. J Nutr 136: 3022-3026.

57. Pou KM, Massaro JM, Hoffmann U, et al, 2007 Visceral and subcutaneous adipose tissue volumes are cross-sectionally related to markers of inflammation and oxidative stress: the Framingham Heart Study. Circulation 116: 1234-1241.

58. Fontana L, Eagon JC, Trujillo ME, Scherer PE, Klein S, 2007 Visceral fat adipokine secretion is associated with systemic inflammation in obese humans. Diabetes 56: 1010-1013.

59. Beckman KB, Ames BN, 1998 The free radical theory of aging matures. Physiol Rev.; 78: 547-581.

60. Finkel T, Holbrook NJ, 2000 Oxidants, oxidative stress and the biology of ageing. Nature 408: 239-247.

61. McEwen BS, 2002 Sex, stress and the hippocampus: allostasis, allostatic load and the aging process. Neurobiol Aging 23: 921-939.

62. Cals MJ, Succari M, Meneguzzer E, et al, 1997 Markers of oxidative stress in fit, health-conscious elderly people living in the Paris area. The Research Group on Ageing (GERBAP). Nutrition 13: 319-326.

63. Kostka T, Drai J, Berthouze SE, Lacour JR, Bonnefoy M, 2000 Physical activity, aerobic capacity and selected markers of oxidative stress and the anti-oxidant defence system in healthy active elderly men. Clin Physiol 20: 185-190.

64. Gidron Y, Russ K, Tissarchondou H, Warner J, 2006 The relation between psychological factors and DNAdamage: a critical review. Biol Psychol 72: 291-304.

65. Moller P, Wallin H, Knudsen LE, 1996 Oxidative stress associated with exercise, psychological stress and lifestyle factors. Chem Biol Interact 102:17-36.

66. Maugeri D, Santangelo A, Bonanno MR, et al, 2004 
Oxidative stress and aging: studies on an East-Sicilian, ultraoctagenarian population living in institutes or at home. Arch Gerontol Geriatr Supp 9: 271-277.

67. Behl C, Lezoualc'h F, Trapp T, Widmann M, Skutella T, Holsboer F, 1997 Glucocorticoids enhance oxidative stress-induced cell death in hippocampal neurons in vitro. Endocrinology 138: 101-106.

68. McIntosh LJ, Sapolsky RM, 1996 Glucocorticoids increase the accumulation of reactive oxygen species and enhance adriamycin-induced toxicity in neuronal culture. Exp Neurol 141: 201-206.

69. Behl C, Skutella T, Lezoualc'h F, et al, 1997 Neuroprotection against oxidative stress by estrogens: structureactivity relationship. Mol Pharmacol 51: 535-541.

70. Kimonides VG, Khatibi NH, Svendsen CN, Sofroniew MV, Herbert J, 1998 Dehydroepiandrosterone (DHEA) and DHEA-sulfate (DHEAS) protect hippocampal neurons against excitatory amino acid-induced neurotoxicity. Proc Natl Acad Sci USA 95: 1852-1857.

71. Kimonides VG, Spillantini MG, Sofroniew MV, Fawcett JW, Herbert J, 1999 Dehydroepiandrosterone antagonizes the neurotoxic effects of corticosterone and translocation of stress-activated protein kinase 3 in hippocampal primary cultures. Neuroscience $89: 429-436$.

72. Liu J, Mori A, 1999 Stress, aging, and brain oxidative damage. Neurochem Res 24: 1479-1497.

73. Irie M, Asami S, Nagata S, Ikeda M, Miyata M, Kasai H, 2001 Psychosocial factors as a potential trigger of oxidative DNA damage in human leukocytes. Jpn J Cancer Res 92: 367-376.

74. Irie M, Asami S, Nagata S, Miyata M, Kasai H, Ikeda M, 2001 Relationships between perceived workload, stress and oxidative DNA damage. Int Arch Occup Environ Health 74: 153-157.

75. Irie M, Asami S, Ikeda M, Kasai H, 2003 Depressive state relates to female oxidative DNA damage via neutrophil activation. Biochem Biophys Res Commun 311: 1014-1018.

76. Epel E, Blackburn E, Lin J, et al, 2004 Accelerated telomere shortening in response to exposure to life stress. PNAS 101:17312-17315.

77. Tsuboi H, Hamer M, Tanaka G, Takagi K, Kinae N, Steptoe A, 2008 Responses of ultra-weak chemiluminescence and secretory $\operatorname{IgA}$ in saliva to the induction of angry and depressive moods. Brain Behav Immun 22: 209-214.

78. Sivonova M, Zitnanova I, Hlincikova L, Skodacek I, Trebaticka J, Durackova Z, 2004 Oxidative stress in university students during examinations. Stress 7: 183188.

79. Forlenza MJ, Miller GE, 2006 Increased serum levels of 8-hydroxy-2'-deoxyguanosine in clinical depression. Psychosom Med 68: 1-7.

80. Singal PK, Beamish RE, Dhalla NS, 1983 Potential oxidative pathways of catecholamines in the formation of lipid peroxides and genesis of heart disease. Adv Exp
Med Biol 161: 391-401.

81. Van Cauter E, Leproult R, Plat L, 2000 Age-related changes in slow wave sleep and REM sleep and relationship with growth hormone and cortisol levels in healthy men. JAMA 284: 861-868.

82. Tannenbaum B, Brindley D, Tannenbaum G, Dallman J, McArthur D, Meaney M, 1997 High-fat feeding alters both basal and stress-induced hypothalamic-pituitary-adrenal activity in the rat. Am J Physiol 273: E1168-1177.

83. Harro J, Rimm H, Harro M, Grauberg M, Karelson K, Atko-Meeme V, 1999 Association of depressiveness with blunted growth hormone response to maximal exercise in young healthy men. Psychoneuroendocrinology 24 : 505-517.

84. Ling PR, Smith RJ, Bistrian BR, 2007 Acute effects of hyperglycemia and hyperinsulinemia on hepatic oxidative stress and the systemic inflammatory response in rats. Crit Care Med 35: 555-560.

85. Roberts CK, Barnard RJ, Sindhu RK, Jurczak M, Ehdaie A, Vaziri ND, 2006 Oxidative stress and dysregulation of NAD(P)H oxidase and antioxidant enzymes in diet-induced metabolic syndrome. Metabolism 55: 928-934.

86. Macias-Gonzalez M, Cardona F, Queipo-Ortuno M, Bernal R, Martin M, Tinahones FJ, 2008 PPARgamma mRNA expression is reduced in peripheral blood mononuclear cells after fat overload in patients with metabolic syndrome. J Nutr 138: 903-907.

87. Rutters F, Nieuwenhuizen AG, Lemmens SG, Born JM, Westerterp-Plantenga MS, 2009 Hyperactivity of the HPA axis is related to dietary restraint in normal weight women. Physiol Behav 96: 315-319.

88. McLean JA, Barr SI, 2003 Cognitive dietary restraint is associated with eating behaviors, lifestyle practices, personality characteristics and menstrual irregularity in college women. Appetite 40: 185-192.

89. Kiefer A, Lin J, Blackburn EH, Epel E, 2008 Dietary Restraint and telomere shortness in younger and older women. Psychosom Med 70: 845-849.

90. Tataranni PA, Larson D, Snitker S, Young J, Flatt J, Ravussin E, 1996 Effects of glucocorticoid on energy metabolism and food intake in humans. Am J Physiol 271: E317-E325.

91. Epel E, Lapidus R, et al, 2001 Stress may add bite to appetite in women: A laboratory study of stress-induced cortisol and eating behavior. Psychoneuroendocrinology 26: 37-49.

92. Chaput JP, Despres JP, Bouchard C, Tremblay A, 2008 The association between sleep duration and weight gain in adults: a 6-year prospective study from the Quebec Family Study. Sleep 31: 517-523.

93. Blackburn EH, 2005 Telomeres and telomerase: their mechanisms of action and the effects of altering their functions. FEBS Lett 579: 859-862.

94. Allsopp RC, Vaziri H, Patterson C, et al, 1992 Telomere length predicts replicative capacity of human fibroblasts. Proc Natl Acad Sci USA 89: 10114-10118. 
95. Blackburn EH, 2000 Telomere states and cell fates. Nature 408: 53-56.

96. Edo MD, Andres V, 2005 Aging, telomeres, and atherosclerosis. Cardiovasc Res 66: 213-221.

97. Chan SW, Blackburn EH, 2003 Telomerase and ATM/ Tel1p protect telomeres from nonhomologous end joining. Mol Cell11: 1379-1387.

98. Brouilette S, Singh RK, Thompson JR, Goodall AH, Samani NJ, 2003 White cell telomere length and risk of premature myocardial infarction. Arterioscler Thromb Vasc Biol 23: 842-846.

99. Samani N, et al, 2001 Telomere shortening in atherosclerosis. Lancet 358: 472-473.

100.Benetos A, Okuda K, Lajemi M, et al, 2001 Telomere length as an indicator of biological aging: the gender effect and relation with pulse pressure and pulse wave velocity. Hypertension 37: 381-385.

101. Jeanclos E, Schork NJ, Kyvik KO, Kimura M, Skurnick JH, Aviv A, 2000 Telomere length inversely correlates with pulse pressure and is highly familial. Hypertension 36: 195-200.

102. Nawrot TS, Staessen JA, Gardner JP, Aviv A, 2004 Telomere length and possible link to $\mathrm{X}$ chromosome. Lancet 363: 507-510.

103. Gardner JP, Li S, Srinivasan SR, et al, 2005 Rise in insulin resistance is associated with escalated telomere attrition. Circulation 111: 2171-2177.

104. Valdes AM, Andrew T, Gardner JP, et al, 2005 Obesity, cigarette smoking, and telomere length in women. Lancet 366: 662-664.

105. Aviv A, Valdes A, Gardner JP, Swaminathan R, Kimura M, Spector TD, 2006 Menopause modifies the association of leukocyte telomere length with insulin resistance and inflammation. J Clin Endocrinol Metab 91: 635-640.

106. Sampson MJ, Winterbone MS, Hughes JC, Dozio N, Hughes DA, 2006 Monocyte telomere shortening and oxidative DNA damage in type 2 diabetes. Diabetes Care 29: 283-289.

107. Cawthon R, Smith K, O’Brien E, Sivatchenko A, Kerber R, 2003 Association between telomere length in blood and mortality in people aged 60 years or older. Lancet 361: 393-395.

108. Fitzpatrick AL, Kronmal RA, Gardner JP, et al, 2006 Leukocyte telomere length and cardiovascular disease in the cardiovascular health study. Am J Epidemiol 165: 14-21.

109. Carrero JJ, Stenvinkel P, Fellstrom B, et al, 2008 Telomere attrition is associated with inflammation, low fetuin-A levels and high mortality in prevalent haemodialysis patients. J Intern Med 263: 302-312.

110. Honig LS, Schupf N, Lee JH, Tang MX, Mayeux R, 2006 Shorter telomeres are associated with mortality in those with APOE epsilon4 and dementia. Ann Neurol 60: 181-187.

111. Martin-Ruiz C, Dickinson HO, Keys B, Rowan E, Kenny RA, Von Zglinicki T, 2006 Telomere length predicts poststroke mortality, dementia, and cognitive decline. Ann Neurol 60: 174-180.

112. Epel E, Lin J, Wilhelm F, et al, 2006 Cell aging in relation to stress arousal and cardiovascular disease risk factors. Psychoneuroendocrinology 31: 277-287.

113. Choi J, Fauce SR, Effros RB, 2008 Reduced telomerase activity in human $\mathrm{T}$ lymphocytes exposed to cortisol. Brain Behav Immun 22: 600-605.

114. Borras C, Esteve JM, Vina JR, Sastre J, Vina J, Pallardo FV, 2004 Glutathione regulates telomerase activity in 3T3 fibroblasts. J Biol Chem 279: 34332-34335.

115. Kurz DJ, Decary S, Hong Y, Trivier E, Akhmedov A, Erusalimsky JD, 2004 Chronic oxidative stress compromises telomere integrity and accelerates the onset of senescence in human endothelial cells. J Cell Sci 117: 2417-2426.

116. von Zglinicki T, Saretzki G, Docke W, Lotze C, 1995 Mild hyperoxia shortens telomeres and inhibits proliferation of fibroblasts: a model for senescence? Exp Cell Res 220: 186-193.

117. Serra V, von Zglinicki T, Lorenz M, Saretzki G, 2003 Extracellular superoxide dismutase is a major antioxidant in human fibroblasts and slows telomere shortening. J Biol Chem 278: 6824-6830.

118. Haendeler J, Hoffmann J, Diehl JF, et al, 2004 Antioxidants inhibit nuclear export of telomerase reverse transcriptase and delay replicative senescence of endothelial cells. Circ Res 94: 768-775.

119. Adaikalakoteswari A, Balasubramanyam M, Mohan V, 2005 Telomere shortening occurs in Asian Indian Type 2 diabetic patients. Diabet Med 22: 1151-1156.

120. Adaikalakoteswari A, Balasubramanyam M, Ravikumar R, Deepa R, Mohan V, 2007 Association of telomere shortening with impaired glucose tolerance and diabetic macroangiopathy. Atherosclerosis 195: 83-89.

121. Demissie S, Levy D, Benjamin EJ, et al, 2006 Insulin resistance, oxidative stress, hypertension, and leukocyte telomere length in men from the Framingham Heart Study. Aging Cell 5: 325-330.

122. Toussaint O, Michiels C, Raes M, Remacle J, 1995 Cellular aging and the importance of energetic factors. Exp Gerontol 30: 1-22.

123. von Zglinicki T, 2002 Oxidative stress shortens telomeres. Trends Biochem Sci 27: 339-344.

124. Gems D, Partridge L, 2008 Stress-response hormesis and aging: "that which does not kill us makes us stronger". Cell Metab 7: 200-203.

125. Parsons PA, 2007 The ecological stress theory of aging and hormesis: an energetic evolutionary model. Biogerontology 8: 233-242.

126. Kultz D, 2005 Molecular and evolutionary basis of the cellular stress response. Annu Rev Physiol 67: 225-257.

127. Lithgow GJ, Kirkwood TB, 1996 Mechanisms and evolution of aging. Science 273: 80.

128. Olsen A, Vantipalli MC, Lithgow GJ, 2006 Lifespan extension of Caenorhabditis elegans following repeated 
mild hormetic heat treatments. Biogerontology 7: 221230.

129. Rattan SI, Derventzi A, 1991 Altered cellular responsiveness during ageing. Bioessays 13: 601-606.

130. Niwa Y, Ishimoto K, Kanoh T, 1990 Induction of superoxide dismutase in leukocytes by paraquat: correlation with age and possible predictor of longevity. Blood 76: 835-841.

131. Ayyadevara S, Alla R, Thaden JJ, Shmookler Reis RJ, 2008 Remarkable longevity and stress resistance of nematode PI3K-null mutants. Aging Cell 7: 13-22.

132. Yamawaki TM, Arantes-Oliveira N, Berman JR, Zhang P, Kenyon C, 2008 Distinct activities of the germline and somatic reproductive tissues in the regulation of Caenorhabditis elegans' longevity. Genetics 178: 513526.

133. Kassi E, Papavassiliou AG, 2008 Could glucose be a proaging factor? J Cell Mol Med 8: 8 .

134. Gan L, Mucke L, 2008 Paths of convergence: sirtuins in aging and neurodegeneration. Neuron 58: 10-14.

135. Michishita E, McCord RA, Berber E, et al, 2008 SIRT6 is a histone $\mathrm{H} 3$ lysine 9 deacetylase that modulates telomeric chromatin. Nature 452: 492-496.

136. Rajawat YS, Bossis I, 2008 Autophagy in aging and in neurodegenerative disorders. Hormones (Athens) 7: 46-61.

137. Hansen M, Chandra A, Mitic LL, Onken B, Driscoll M, Kenyon C, 2008 A role for autophagy in the extension of lifespan by dietary restriction in C. elegans. PLoS Genet 4: e24.

138. Pfeifer U, Warmuth-Metz M, 1983 Inhibition by insulin of cellular autophagy in proximal tubular cells of rat kidney. Am J Physiol 244: E109-114.

139. Florez-McClure ML, Hohsfield LA, Fonte G, Bealor MT, Link CD, 2007 Decreased insulin-receptor signaling promotes the autophagic degradation of beta-amyloid peptide in C. elegans. Autophagy 3: 569-580.

140. Kalamidas SA, Kotoulas OB, 2000 Studies on the breakdown of glycogen in the lysosomes: the effects of hydrocortisone. Histol Histopathol 15: 29-35.

141. Salas M, Tuchweber B, Kourounakis P, 1980 Liver ultrastructure during acute stress. Pathol Res Pract 167: 217-233.

142. Viveros MP, Arranz L, Hernanz A, Miquel J, De la Fuente M, 2007 A model of premature aging in mice based on altered stress-related behavioral response and immunosenescence. Neuroimmunomodulation 14: 157162.

143. Gilad GM, Gilad VH, 1995 Strain, stress, neurodegeneration and longevity. Mech Ageing Dev 78: 75-83.

144. Korte SM, Koolhaas JM, Wingfield JC, McEwen BS, 2005 The Darwinian concept of stress: benefits of allostasis and costs of allostatic load and the trade-offs in health and disease. Neurosci Biobehav Rev 29: 3-38.

145. Dickerson SS, Kemeny ME, 2004 Acute stressors and cortisol responses: a theoretical integration and synthesis of laboratory research. Psychol Bull 130: 355-391.

146. Pruessner JC, Baldwin MW, Dedovic K, et al, 2005 Self-esteem, locus of control, hippocampal volume, and cortisol regulation in young and old adulthood. Neuroimage 28: 815-816.

147. Schwartz CE, Wright CI, Shin LM, Kagan J, Rauch SL, 2003 Inhibited and uninhibited infants "grown up": adult amygdalar response to novelty. Science 300: 19521953.

148. Rubino V, Blasi G, Latorre V, et al, 2007 Activity in medial prefrontal cortex during cognitive evaluation of threatening stimuli as a function of personality style. Brain Res Bull 74: 250-257.

149. Denollet J, Sys SU, Stroobant N, Rombouts H, Gillebert TC, Brutsaert DL, 1996 Personality as independent predictor of long-term mortality in patients with coronary heart disease. Lancet 347: 417-421.

150. Pedersen SS, Denollet J, 2003 Type D personality, cardiac events, and impaired quality of life: a review. Eur J Cardiovasc Prev Rehabil 10: 241-248.

151. O'Donovan A, Lin J, Dhabhar FS, et al, 2008 Pessimism correlates with leukocyte telomere shortness and elevated interleukin-6 in post-menopausal women. Brain Behav Immun 11: 11.

152. Eisenberger NI, Taylor SE, Gable SL, Hilmert CJ, Lieberman MD, 2007 Neural pathways link social support to attenuated neuroendocrine stress responses. Neuroimage 35: 1601-1612.

153. Canli T, Qiu M, Omura K, et al, 2006 Neural correlates of epigenesis. Proc Natl Acad Sci USA 103: 16033-16038.

154. Cotman CW, Berchtold NC, 2002 Exercise: a behavioral intervention to enhance brain health and plasticity. Trends Neurosci 25: 295-301.

155. Traustadottir T, Bosch PR, Matt KS, 2005 The HPA axis response to stress in women: effects of aging and fitness. Psychoneuroendocrinology 30: 392-402.

156. Georgiades A, Sherwood A, Gullette EC, et al, 2000 Effects of exercise and weight loss on mental stress-induced cardiovascular responses in individuals with high blood pressure. Hypertension 36: 171-176.

157. Petruzzello SJ, Landers DM, Hatfield BD, Kubitz KA, Salazar W, 1991 A meta-analysis on the anxiety-reducing effects of acute and chronic exercise. Outcomes and mechanisms. Sports Med 11: 143-182.

158. Barbour KA, Edenfield TM, Blumenthal JA, 2007 Exercise as a treatment for depression and other psychiatric disorders: a review. J Cardiopulm Rehabil Prev 27: 359367.

159. Wolkowitz O, Epel E, Reus V 2001 Antiglucocorticoid strategies in treating major depression and allostatic load. In: Jogin T, (ed) The Physical Consequences of Depression. Philadelphia, PA: Wrightson Biomedical Publishing; pp, 181-213.

160. Arnetz BB, Theorell T, Levi L, Kallner A, Eneroth P, 1983 An experimental study of social isolation of elderly people: psychoendocrine and metabolic effects. Psycho- 
somatic Med 45: 395-406.

161. Antoni MH, 2003 Stress management effects on psychological, endocrinological, and immune functioning in men with HIV infection: empirical support for a psychoneuroimmunological model. Stress 6: 173-188.

162. Banerjee B, Vadiraj HS, Ram A, et al, 2007 Effects of an integrated yoga program in modulating psychological stress and radiation-induced genotoxic stress in breast cancer patients undergoing radiotherapy. Integr Cancer Ther 6: 242-250.

163. Roberts CK, Won D, Pruthi S, Lin SS, Barnard RJ, 2006 Effect of a diet and exercise intervention on oxidative stress, inflammation and monocyte adhesion in diabetic men. Diabetes Res Clin Pract 73: 249-259.

164. Ornish D, Lin J, Daubenmier J, et al, 2008, Increased telomerase activity and comprehensive lifestyle changes: a pilot study. Lancet Oncol 9: 1048-1057.
165.Piper MD, Bartke A, 2008 Diet and aging. Cell Metab 8: 99-104.

166. Redman LM, Martin CK, Williamson DA, Ravussin E, 2008 Effect of caloric restriction in non-obese humans on physiological, psychological and behavioral outcomes. Physiol Behav 94: 643-648.

167. Katic M, Kahn CR, 2005 The role of insulin and IGF-1 signaling in longevity. Cell Mol Life Sci 62: 320-343.

168. Roth GS, Lane MA, Ingram DK, et al, 2002 Biomarkers of caloric restriction may predict longevity in humans. Science 297: 811

169. Picard F, Kurtev M, Chung N, et al, 2004 Sirt1 promotes fat mobilization in white adipocytes by repressing PPARgamma. Nature 429: 771-776.

170. Sapolsky R 2004 Why zebras don’t get ulcers: An updated guide to stress, stress-related diseases, and coping. New York: Henry Holt and Co. 